Article

\title{
Implementing Morpholino-Based Nucleic Acid Sensing on a Portable Surface Plasmon Resonance Instrument for Future Application in Environmental Monitoring
}

\author{
Andrea Bagi ${ }^{1, *,+} \oplus$, Scott D. Soelberg ${ }^{2}$, Clement E. Furlong ${ }^{2}$ and Thierry Baussant ${ }^{1,+}$ \\ 1 International Research Institute of Stavanger, 4068 Stavanger, Norway; Thierry.Baussant@norceresearch.no \\ 2 Departments of Medicine-Division of Medical Genetics and Genome Sciences, University of Washington, \\ Seattle, WA 98195-5852, USA; scottjs@uw.edu (S.D.S.); clem@u.washington.edu (C.E.F.) \\ * Correspondence: anba@norceresearch.no; Tel.: +47-4664-0398 \\ + The International Research Institute of Stavanger will become part of (and renamed to): \\ "NORCE Norwegian Research Center" from the first of October 2018.
}

Received: 3 September 2018; Accepted: 26 September 2018; Published: 28 September 2018

\begin{abstract}
A portable surface plasmon resonance (SPR) instrument was tested for the first time for the detection of oligonucleotide sequences derived from the 16S rRNA gene of Oleispira antarctica RB-8, a bioindicator species of marine oil contamination, using morpholino-functionalized sensor surfaces. We evaluated the stability and specificity of morpholino coated sensor surfaces and tested two signal amplification regimes: (1) sequential injection of sample followed by magnetic bead amplifier and (2) a single injection of magnetic bead captured oligo. We found that the sensor surfaces could be regenerated for at least 85 consecutive sample injections without significant loss of signal intensity. Regarding specificity, the assay clearly differentiated analytes with only one or two mismatches. Signal intensities of mismatch oligos were lower than the exact match target at identical concentrations down to $200 \mathrm{nM}$, in standard phosphate buffered saline with $0.1 \%$ Tween-20 added. Signal amplification was achieved with both strategies; however, significantly higher response was observed with the sequential approach (up to 16-fold), where first the binding of biotin-probe-labeled target oligo took place on the sensor surface, followed by the binding of the streptavidin magnetic beads onto the immobilized targets. Our experiments so far indicate that a simple coating procedure in combination with a relatively cost-efficient magnetic-bead-based signal amplification will provide robust SPR based nucleic acid sensing down to $0.5 \mathrm{nM}$ of a 45 -nucleotide long oligo target $(7.2 \mathrm{ng} / \mathrm{mL})$.
\end{abstract}

Keywords: surface plasmon resonance; $16 \mathrm{~S}$ rRNA; bacterial detection; hydrocarbon biodegradation; magnetic bead based biosensing; portable biosensor

\section{Introduction}

Molecular techniques in general, and more specifically, nucleic acid sensing techniques are gradually replacing standard cultivation-dependent laboratory methods in both the public health sector, and environmental monitoring [1-5]. Biosensors in particular are very promising due to their versatility and suitability for miniaturization and integration in autonomous devices [6-8]. A number of signal transduction mechanisms exist and have been explored over the last decades for nucleic acid biosensing. Electrochemical sensors are utilized in the majority of the studies reviewed recently by Du et al. [9]. Surface plasmon resonance (SPR) is a relatively young approach in nucleic acid biosensing, nevertheless it is becoming a popular tool for label-free sensing of a variety of analytes $[10,11]$. To mention a few nucleic acid sensing examples, SPR has been applied for bacterial 
$16 \mathrm{~S}$ rRNA, single-nucleotide polymorphism and microRNA detection [12-14]. SPR sensing is also currently being implemented on the third generation environmental sample processor (3G-ESP), a device capable of fully autonomous sample collection, analysis, and data transmission over extended deployment periods in the pelagic marine environment [15]. More specifically, the custom-made portable SPR instrument used in this study [16] has been integrated into the 3G-ESP recently. In situ ocean observing systems, such as the ESP have long been recognized as promising tools to provide real-time and high-resolution spatiotemporal data for risk assessment and monitoring of marine environments. Tools like ESP are needed especially in the new frontier of future oil and gas exploration and production activities, i.e., the Arctic and deep waters, to address the problems associated with traditional monitoring approaches [17-19]. Autonomous devices equipped with molecular tools can rapidly detect changes in environmental indicators, including bacterial species that are well-known to respond quickly to oil discharges. Among the obligate hydrocarbon (HC) degraders, the genus Oleispira is one of the most commonly reported cold-adapted alkane degrading genus. It has been identified both in deep-water sediments and the pelagic zone of cold marine habitats. Its genome has been sequenced and biodegradation potential mapped using various HC sources [20,21]. Oleispira was also among the HC-degraders monitored by Królicka et al. who proposed the use of mainly obligate HC degrading bacterial indicator species for the detection of oil leaks [22]. Their study showed the potential application of qPCR quantification of Oleispira antarctia 16S rRNA gene copy number as an indicator of oil exposure, using DNA extraction and qPCR protocols mimicking 2G-ESP procedures. Nevertheless, qPCR is a rather complex and time-consuming technique in comparison to nucleic acid sensing, particularly label-free SPR. SPR-based nucleic acid sensing can be achieved using various recognition elements, including natural DNA oligonucleotides and artificial analogues, such as peptide nucleic acids (PNA), linked nucleic acids (LNA), and morpholinos [23]. These analogues have properties such as better stability on the sensor surface and higher binding strength in comparison to natural DNA probes. Morpholinos are of particular interest as they are extremely stable and show a number of other advantages over their natural DNA counterparts and the other synthetic analogues [24]. Morpholinos are mainly used for in vivo silencing and knock-out experiments due to their resistance to enzymatic degradation [25]. Nevertheless, they are becoming increasingly used in biosensing and biodistribution measurements [26]. The SPR instrument developed in 2007 [16] has so far been used for antibody-based assays, with the aim to detect small molecules, as well as viruses and whole bacteria. Its sensor chip can also be coated with other types of recognition molecules. In this study, we have explored morpholinos as recognition elements to be applied for nucleic acid sensing on this platform. We chose to work with synthetic oligonucleotides representing the 16S rRNA gene sequence of Oleispira antarctica RB-8 in order to develop an assay for future use in 16S rRNA based environmental monitoring of oil pollution events. Our goals were: (1) to test whether an extremely simple coating procedure using morpholinos as recognition elements can provide suitable and robust (regenerable) sensor surface, (2) to assess the specificity of the assay, and (3) to test magnetic-bead-based signal amplification strategies.

\section{Materials and Methods}

\subsection{General Assay Procedures and Materials}

\subsubsection{SPR Instrument}

All experiments were carried out with a 4-chip, 12-channel portable SPR instrument (Figure 1) manufactured at the University of Washington (Seattle, WA, USA). The current model is a modified version of the instrument described in [27]. The system is housed in a $27 \times 25 \times 12 \mathrm{~cm}$ case and incorporates miniature electronic and fluidic components. It includes temperature control and conditioning of the injected sample $\left(\approx \pm 0.01{ }^{\circ} \mathrm{C}\right)$, which is a critical parameter of SPR use in field applications or for autonomous environmental sensor applications. The four-chip system is low power ( 2.6 watts average at 12 volts) and has low flow cell volume $(1 \mu \mathrm{L}$ per channel) and can be used as a 12-channel system. A computer graphical user interface (GUI) was also developed for data display 
and system control. The system was also designed to run semi-autonomously. Autonomous operation requires a 'start' signal be sent, followed by a sample being pumped or injected into the holding loop by the user or an outside sample processor. The system then processes the injected sample automatically through a series of low power/low dead-volume valves. Following a detection sequence, the system automatically performs a regeneration sequence by flowing a regeneration solution over the surface followed by flow of starting buffer to reset the system for another detection cycle.

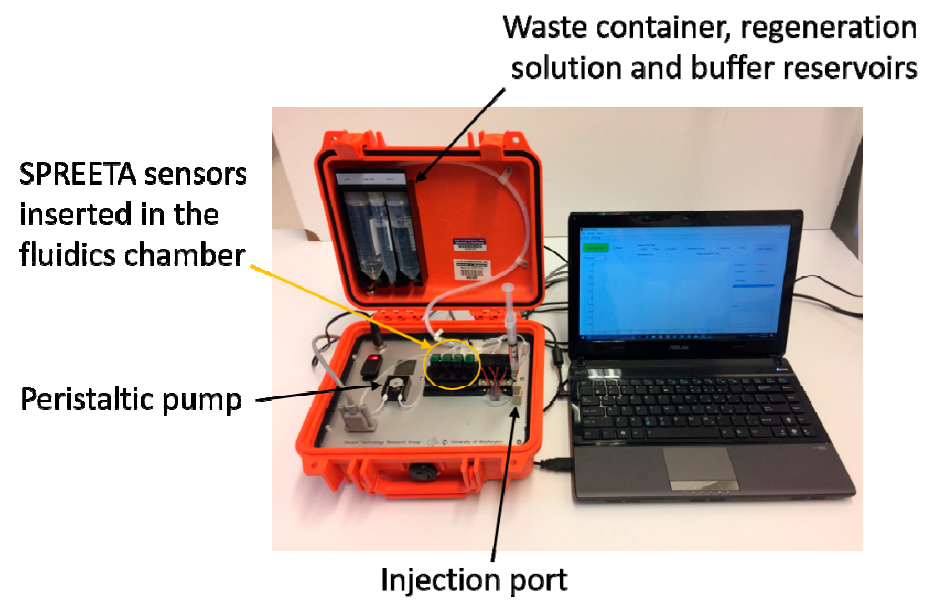

Figure 1. Photo of the portable surface plasmon resonance instrument connected to a 13" laptop.

\subsubsection{Probes}

A 24-nucleotide hybridization probe previously used in a sandwich hybridization assay (personal communication Królicka, A.) was employed as the surface immobilized detection probe (DP). A morpholino oligo of this DP sequence with a disulfide-amide modification at the $3^{\prime}$ end was purchased from Gene Tools LLC (Philomath, OR, USA). The disulfide-amide modification at the $3^{\prime}$ end was used for attachment of the morpholino to the gold sensor surface. DP was checked against the Silva small subunit ribosomal RNA (16S SSU) database (Version 132, on 3 September 2019) using the online SILVA probe match and evaluation tool, TestProbe 3.0 [28]. Hits with 0 mismatches all belonged to the genus Oleispira, confirming the specificity of the DP probe. A previously published universal bacterial primer was used as the capture probe (CP) [29]. This was purchased in 5'-biotinylated DNA oligo form (IDT, San Jose, CA, USA). Sequences are shown in Table 1.

Table 1. Sequences of probes and target analyte oligonucleotides

\begin{tabular}{crc}
\hline Name & Sequence $\mathbf{( 5}^{\prime} \mathbf{- 3}^{\prime} \mathbf{)}$ & $\mathbf{M W}(\mathbf{g} / \mathbf{m o l})$ \\
\hline DP & CTAGCTAATCTCACTCAGGCTCAT-S-S-amide & 8243 \\
CP & Bio-TCTACGCATTTCACCGCTACA & 6706 \\
REF & ATGAGCCTGAGTGAGATTAGCTAG & 7457 \\
PC & ATGAGCCTGAGTGAGATTAGCTAG/iSp18/TGTAGCGGTGAAATGCGTAGA & 14,368 \\
M1 & ATGAACCTGAGTGAGATTAGCTAG & 7441 \\
M2 & ATGAACCTGAGTTAGATTAGCTAG & 7416 \\
NC & TGTAGCGGTGAAATGCGTAGA & 6550 \\
\hline
\end{tabular}

S-S-amide = disulfide-amide modification. Bio = biotin modification. Mismatched nucleotides in M1 (1 mismatch containing oligo) and M2 (2 mismatch containing oligo) are highlighted in bold and underlined. DP = detection probe, $\mathrm{CP}=$ capture probe, $\mathrm{REF}=$ reference Oleispira oligo, $\mathrm{PC}=$ positive control combined oligo, and $\mathrm{NC}=$ negative control (non-complementary oligo).

\subsubsection{Analytes}

A 24-nucleotide-long segment of the Oleispira 16S rRNA gene (100\% complementary to DP) was used as a reference sequence (REF) in all experiments, while a 45-nucleotide long combined 
oligo, complementary to both $\mathrm{DP}$ and $\mathrm{CP}$ was used as positive control (PC) in the amplification tests. PC contained an internal spacer (iSp18, an 18-mer hexa-ethylene-glycol spacer) between the segments complementary to DP and CP. For specificity testing, mismatched oligos containing 1 (M1) or 2 (M2) mismatches to DP were used. To test specificity, an oligo complementary to the universal CP was used as a negative control (NC, 15 mismatches to REF). Sequences are summarized in Table 1.

\subsubsection{Buffers}

Dulbecco's phosphate buffered saline (DPBS) purchased from Sigma-Aldrich Norway AS (Oslo, Norway) containing $\mathrm{KCl}(0.2 \mathrm{~g} / \mathrm{L}), \mathrm{NaCl}(8.0 \mathrm{~g} / \mathrm{L}), \mathrm{KH}_{2} \mathrm{PO}_{4}(0.2 \mathrm{~g} / \mathrm{L})$, anhydrous $\mathrm{Na}_{2} \mathrm{HPO}_{4}$ $(1.15 \mathrm{~g} / \mathrm{L})$, and DPBS amended with $0.1 \%$ Tween-20 (DPBS-T) were used as hybridization and running buffer solutions, respectively. A $50 \mathrm{mM} \mathrm{NaOH}$ denaturing solution was used for regenerating the SPR surfaces.

\subsubsection{Preparation of Sensor Surfaces}

Gold surfaces of the SPR sensors were cleaned with a piranha solution (Caution: piranha solution is extremely oxidizing and must not be stored in tightly capped containers on account of gas evolution) prepared by slowly adding $30 \% \mathrm{H}_{2} \mathrm{O}_{2}$ to a concentrated sulfuric acid solution (three drops $\mathrm{H}_{2} \mathrm{O}_{2}$ added to nine drops $\mathrm{H}_{2} \mathrm{SO}_{4}$ ). Approximately $40 \mu \mathrm{L}$ of this solution was used to cover the gold surface of the sensor for $20 \mathrm{~min}$. The sensor surfaces were then washed with deionized water. Morpholino stock ( $1 \mathrm{mM}$ in molecular grade water) was first diluted to $100 \mu \mathrm{M}$ in DPBS, then a $20 \mu \mathrm{L}$ droplet was carefully applied onto the clean gold surface of a sensor chip. Coated sensors were incubated at room temperature in a dark humid chamber at least overnight. Prior to use, the gold surface was rinsed with $1 \mathrm{~mL}$ DPBS-T, placed in the sensor slot and referenced with sucrose solution $(30 \mathrm{w} / \mathrm{v} \%)$. For storage, the functionalized surfaces were wicked dry and then stored in a plastic case under dark and dry conditions for up to two months.

\subsubsection{Experimental Procedures}

Each analysis was performed using the fluidics program outlined in Table 2. Note that the baseline was established during the two-minute-long initialization step, then the sensors were 'zeroed' during the baseline step. The fluidics program was slightly modified for testing the sequential approach, where an additional injection step and subsequent flow and flush steps were included. The total duration of one measurement was between 12 and $24 \mathrm{~min}$, with binding time kept constant at $6 \mathrm{~min}$ with a flush step after $4 \mathrm{~min}$.

Table 2. Fluidics program set-up showing the duration and flow rate (controlled by the peristaltic pump) of either buffer (during initialization, binding, and flow) or regeneration solution (during regeneration) for each programmed step.

\begin{tabular}{ccc}
\hline Step & Duration $(s)$ & Pump Speed $(\mu \mathrm{L} / \mathrm{min})$ \\
\hline Initialization & 120 & 20 \\
Baseline & 0 & 0 \\
Injection & 10 & 0 \\
Flow & 240 & 20 \\
Flush & 7 & n.a. \\
Flow & 120 & 20 \\
Regeneration & 120 & 100 \\
Flow & 120 & 100
\end{tabular}

n.a. = not applicable. The flow rate at the flush step is constant $5 \mathrm{~mL} / \mathrm{min}$, regulated by the air pump.

To monitor stability and potential degradation of the signal, a $500 \mu \mathrm{L}$ aliquot of the reference oligo (REF) at $5 \mu \mathrm{M}$ concentration was injected and analyzed at the beginning and at the end of each 
experiment. RIU values at 6 min were recorded and tracked over time. Similarly, the signal of buffer injections was also tracked.

\subsubsection{Preparation of Oligos and Magnetic Beads}

All oligos were prepared in molecular grade water as $1 \mathrm{mM}$ concentration stocks and stored at $4{ }^{\circ} \mathrm{C}$. These were diluted in DPBS-T prior to injection and analysis unless otherwise stated. Streptavidin coated magnetic beads (500 nm diameter, $2 \mathrm{mg} / \mathrm{mL}$, BD IMag ${ }^{\mathrm{TM}}$ Streptavidin Particles Plus-DM, catalog no. 557812, BD Biosciences, Franklin Lakes, NJ, USA) were washed twice in DPBS and were resuspended in DPBS, in a volume equal to that taken from the original stock. This solution is subsequently called: $1 \times$ beads.

\subsection{Testing Specificity}

The reference sequence (REF), two mismatch oligos (M1 and M2), and a negative control (NC) oligo were injected at various concentrations $(50-5000 \mathrm{nM})$ and RIU values recorded after 6 min of binding were compared. A buffer injection was always carried out between different samples and the RIU values of these injections were used as background values. Oligos were diluted in DPBS-T to final concentrations of 50, 200, 1000, or $5000 \mathrm{nM}$. Measurements were carried out in triplicate except for the $5000 \mathrm{nM}$ samples. Pairwise comparisons between the signal of different oligos at a given concentration were carried out with JMP 5.1 software using Student's $t$-test $(\alpha=0.05)$.

\subsection{Testing Two Signal Amplification Strategies}

\subsubsection{Sequential Assay}

PC oligo and biotin labeled CP probe stock solutions $(1 \mathrm{mM})$ were diluted 10-fold in DPBS buffer. Then $2.5 \mu \mathrm{L}$ of diluted PC $(100 \mu \mathrm{M})$ and $2.5 \mu \mathrm{L}$ of diluted CP $(100 \mu \mathrm{M})$ were mixed and allowed to hybridize for $20 \mathrm{~min}$ at room temperature (approx. $20^{\circ} \mathrm{C}$ ). DPBS-T buffer $(495 \mu \mathrm{L}$ ) was then added and the hybridized oligo and probe complex was injected. The binding curve was recorded for $6 \mathrm{~min}$ then $1 \times$ beads $(5,10,25$, or $50 \mu \mathrm{L}=10,20,50$, and $100 \mu \mathrm{g}$, respectively) resuspended in DPBS-T (final volume of $500 \mu \mathrm{L}$ ) were injected for the amplification step (Figure 2B). Refractive index units (RIU) values were recorded after $6 \mathrm{~min}$. Measurements were carried out in triplicates. The signal of the bead solution alone was also recorded in triplicate at the beginning of the experiment for each bead concentration as background and subtracted from the sample signals.

\subsubsection{Capture Assay}

PC oligo and biotin labeled CP probe stock solutions $(1 \mathrm{mM})$ were diluted 10-fold in DPBS buffer, then $2.5 \mu \mathrm{L}$ diluted PC $(100 \mu \mathrm{M})$ and $2.5 \mu \mathrm{L}$ diluted $\mathrm{CP}(100 \mu \mathrm{M})$ was mixed and allowed to hybridize for $20 \mathrm{~min}$ at room temperature (approx. $20{ }^{\circ} \mathrm{C}$ ). Afterwards, DPBS buffer (445-490 $\mu \mathrm{L}$ depending on the volume of streptavidin beads) and $1 \times$ beads $(5,10,25$, or $50 \mu \mathrm{L}=10,20,50$, and $100 \mu \mathrm{g}$, respectively) were added and mixed. Following a $10 \mathrm{~min}$ incubation at room temperature, the mix was placed on a magnetic rack and separation was carried out for at least $10 \mathrm{~min}$. Supernatant was then removed with a pipette, conjugated beads were resuspended in $500 \mu \mathrm{L}$ DPBS-T running buffer and injected immediately (Figure 2A). RIU values were recorded after $6 \mathrm{~min}$. Measurements were carried out in triplicates. 
A
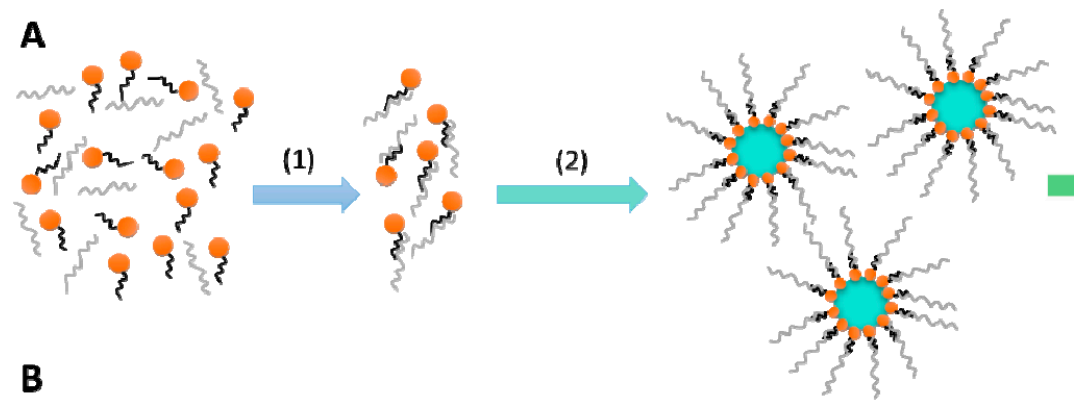

B

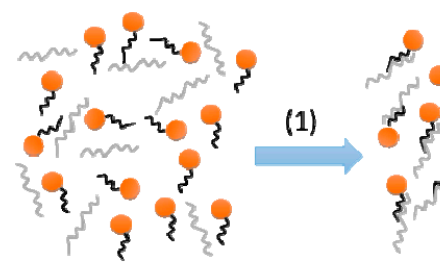

Combined oligo (PC)

Biotin labeled capture probe (CP)
(2)

(2)

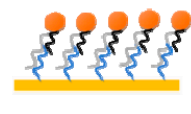

(3)

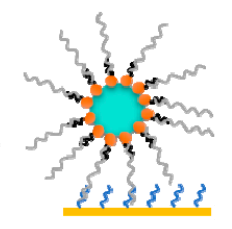

(3)

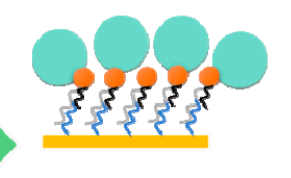

\section{Streptavidin coated magnetic bead}

Morpholino oligo (DP) functionalized sensor surface

Figure 2. Illustration of the two different amplification strategies: capture approach (A) and sequential approach (B). The first step (1) was identical in both cases: the hybridization of positive control (PC) oligo with the biotin labeled capture probe (CP) took place. The second step (2) in the capture approach was to conjugate the biotin labeled hybridized oligo-probe complex to the streptavidin coated magnetic beads, while in the sequential approach, the oligo-probe complex was injected and its binding to the morpholino functionalized surface was recorded. Finally, in the third step (3) of the capture approach, oligo-probe complex conjugated magnetic beads were injected and a single binding curve was recorded. In case of the sequential approach, streptavidin coated magnetic beads were injected and the second binding curve, binding of beads to immobilized biotin-labeled oligo-probe complex was recorded.

\subsection{Testing the Detection Limits}

Detection limits were tested using the REF oligo alone and using the PC oligo in combination with sequential magnetic bead signal amplification. For the first experiment, a serial dilution of the REF oligo samples at concentrations of 50, 200, 500, 1000, and $5000 \mathrm{nM}$ were analyzed using the same fluidics program described in Table 2. For the second experiment, a 10-fold serial dilution of the PC oligo $(0.1-100 \mu \mathrm{M})$ was prepared and assays were carried out as described for the sequential approach with final concentrations of PC at $0.5,5,50$, and $500 \mathrm{nM}$. The concentration of CP probe working solution was kept constant at $100 \mu \mathrm{M}$ for all tested PC concentrations to ensure excess. All measurements were carried out in triplicates.

\section{Results and Discussion}

\subsection{General Assay Procedures}

Preparation of SPR sensor surfaces can require elaborate procedures (largely depending on the chemistry used for binding the oligo to the gold surface) in order to ensure optimal coverage, probe orientation, and to minimize the surface area of bare-gold sites available for non-specific adsorption [30]. This is however not always necessary, instead rather simple coating procedures can be sufficient to improve the orientation of the DNA probes and to attenuate non-specific binding, such as a short post-treatment with 6-mercapto-1-hexanol [12] or using 11-mercaptoundecanoic acid as a linker for immobilizing ssDNA probes [31]. Surface passivation of thiol-modified morpholino coated sensors can be performed similarly by applying short alkanethiols, but this process requires careful optimization of alkanethiol concentration and incubation time [32]. Our approach was even simpler, similar to the strategy reported by Liu et al. [33]. After cleaning the surfaces with piranha solution, the morpholino 
layer was created by incubating the surface with a droplet $(20 \mu \mathrm{L})$ of concentrated $(100 \mu \mathrm{M})$ morpholino probe solution overnight. The disulfide-amide modification used here, in contrast to the more widely used thiol $(-\mathrm{SH})$ modification, enabled a strong and long-lasting bond between the gold surface and the morpholino probes. Measurement results of the REF oligo were nearly constant for over 85 sample injections (approx. 100 regeneration cycles) with no significant decrease in signal intensity as shown in Figure 3. This ability of maintaining responsivity (reusability) for such a large number of samples (i.e., regeneration cycles) is extremely advantageous when considering potential long-term deployment of automated remote sensing equipment.

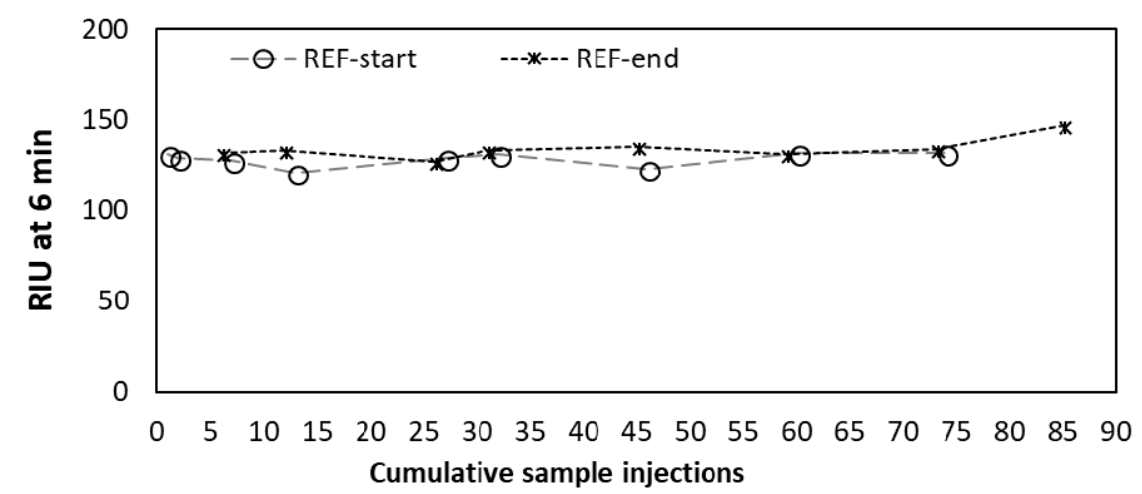

Figure 3. Refractive index unit (RIU) measured after 6 min of incubation for the reference sequence (REF) at the beginning (REF-start) and at the end (REF-end) of each experiment.

A possible reason for such a robust surface, besides the nature of sulfhydryl linkage, might be due to the high probe coverage of the sensor (Figure 4). The gold surface area on the SPREETA chip is approximately $4.5 \times 9.5 \mathrm{~mm}\left(0.4275 \mathrm{~cm}^{2}\right)$. During the coating procedure $\sim 10^{21}$ molecules are introduced onto this area. Theoretically, this could result is a coverage of $2.8 \times 10^{21} \mathrm{molecules} / \mathrm{cm}^{2}$ if all molecules could form a sulfhydryl linkage with the gold surface, however this is unlikely. A maximum coverage can be estimated assuming that the diameter of the morpholino probe is similar to ssDNA $(\sim 0.5 \mathrm{~nm})$ [34], hence the area occupied by a single probe would be $0.785 \mathrm{~nm}^{2}$ leading to an estimate for the maximum number of molecules (of the DP probe) to attach to be $\sim 5.4 \times 10^{13}$. This is much closer to the coverage reported for a morpholino based biosensor (on the order of magnitude $\sim 10^{12}$ molecules $/ \mathrm{cm}^{2}$ ) [35]. The coverage of the sensors used here was most likely higher than the minimum coverage established for a surface plasmon diffraction sensor $\left(\sim 1.1 \times 10^{11}\right.$ molecules $\left./ \mathrm{cm}^{2}\right)$ [36]. For comparison, an optimal morpholino monolayer was prepared by incubation with $0.25 \mu \mathrm{M}$ solution (in deionized water) resulting in $5 \times 10^{12}$ probes $/ \mathrm{cm}^{2}$ for an electrochemical sensor [32] while a self-assembled DNA oligo layer was prepared by incubating $10 \mu \mathrm{L}$ of a $10 \mathrm{ng} / \mu \mathrm{L}(1 \mu \mathrm{M})$ concentration oligo solution on a gold surface by [33]. The large excess of morpholino introduced to the gold surface used in this study, most likely resulted in maximal coverage, ensuring high enough density of the morpholino probes on the SPR chip, leaving no bare-gold sites for non-specific adsorption (Figure 4). This may have also been the reason for the observed low levels of non-specific adsorption on morpholino coated sensors in comparison to bare-gold surfaces used as control (data not shown). 


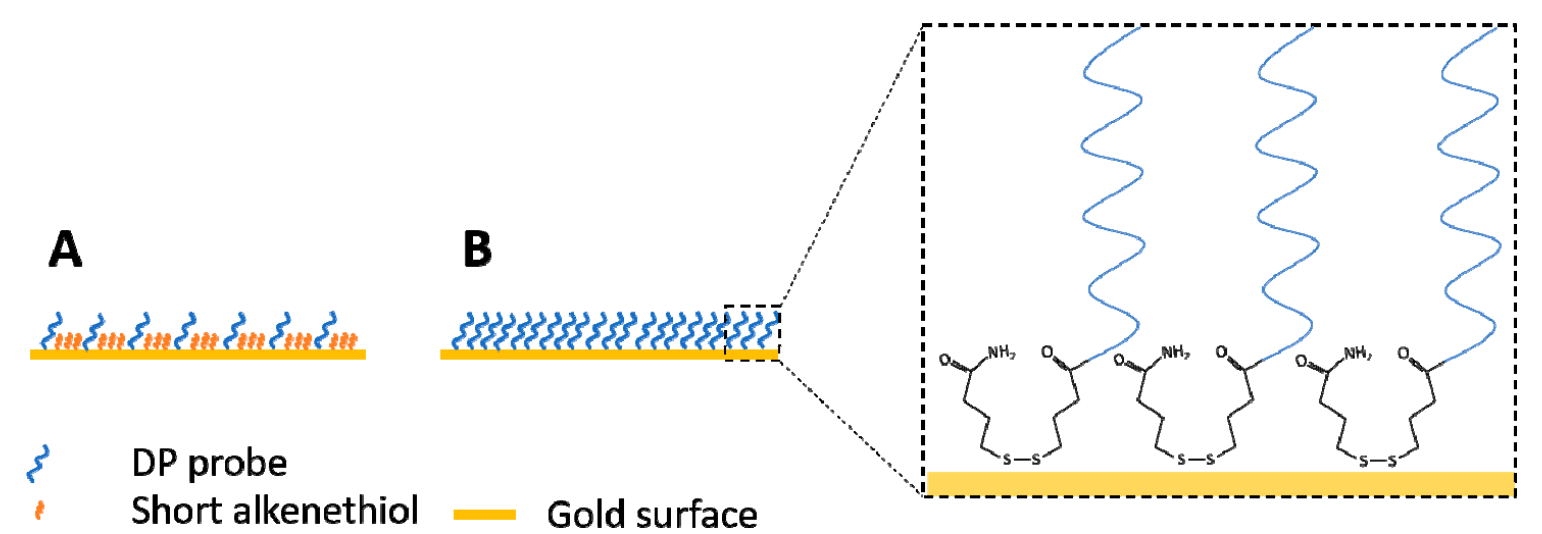

Figure 4. Illustration of the potential difference between a short alkanethiol passivated gold surface with lower probe coverage (A) and a high-density probe coverage without passivation step such as the case in this study (B). Chemical structure of the disulfide-amide modification at the $3^{\prime}$-end of the morpholino oligos is shown in the inset. DP probe $=$ detection probe.

\subsection{Testing Specificity}

Morpholino probe-based biosensors are expected to exhibit superior selectivity over DNA oligo-based counterparts as mismatches have a higher destabilizing effect on morpholino-DNA hybrids than on DNA-DNA hybrids [23]. Morpholino-functionalized electrochemical biosensors in particular have reported high specificity discriminating one mismatch target from $100 \%$ complementary targets [29,36]. Observed lower affinity of morpholino probes, in comparison the DNA probes, was hypothesized to be responsible for enhanced selectivity-since longer perfect match regions are necessary for a high-enough-affinity binding between morpholino probe and its DNA target [37]. Moreover, morpholino-DNA hybrids can be formed at such low salt concentrations, which would normally prohibit DNA-DNA hybridization. While the binding affinity of morpholino probes towards DNA in solution is insensitive to the ionic strength of the buffer, surface immobilized morpholinos exhibit faster binding kinetics under high salt concentrations [23]. Signal intensity for the $100 \%$ complementary oligo (REF), 1 mismatch (M1), 2 mismatch (M2), and non-complementary (NC) sequences in this study, was recorded at four different oligo concentrations using a medium salt buffer ( $150 \mathrm{mM} \mathrm{NaCl}$ in DPBS-T) (Figure 5, Left panel). As expected, the REF oligo gave the highest signal intensity, except for the lowest tested concentration $(50 \mathrm{nM})$ where surprisingly the 1 mismatch containing oligo gave a higher signal, although the difference between REF and M1 was not significant (Student's $t$-test, $p>0.05$ ). The non-complementary sequence (containing 15 mismatches to DP) was nearly indistinguishable from the background (buffer injected), except for the $200 \mathrm{nM}$ case where it was higher than the buffer signal, again, the difference was not significant (Student's $t$-test, $p>0.05$ ). DNA-probe based studies often reported similar results, in the sense that DNA or RNA analytes with only one or two mismatches give relatively high signals [38,39]. In contrast, a morpholino capture probe based electrochemical sensor for microRNA showed excellent selectivity at $100 \mathrm{fM}$ miRNA concentration, with a signal of the one-mismatch target being $7 \%$ and a signal of the two-mismatch target being only $2 \%$ of the signal measured for the fully complementary sequence [40]. This was most likely achievable as a result of the temperature control employed, namely that the hybridization step took place at $60{ }^{\circ} \mathrm{C}$ ensuring specific annealing of probe to template. Such temperature control is usually not incorporated in SPR systems, which generally seem to struggle with mismatched targets containing only one or two mismatched oligonucleotides. Even a highly sensitive assay presented by Ding et al. [14] was characterized by a signal of the one-mismatch target being approx. $20 \%$ of the fully complementary sequence at $10 \mathrm{nM}$. This value dropped to approx. $16 \%$ at the $1 \mathrm{nM}$ concentration level. Nevertheless, the signal intensity of the one- and two-mismatch targets at such low concentration ( 1 and $10 \mathrm{nM}$ ) was very close to that of the background while the $100 \%$ complementary target was significantly higher. It will be interesting to perform a mismatch test with an optimized amplification 
protocol and assess the selectivity of our assay at lower than $50 \mathrm{nM}$ concentration. Finally, it is worth noting that one way proposed to distinguish mismatched oligos in case of DNA-DNA hybridization, was to compare the kinetics of the rinsing step, as the mismatched targets were apparently washed out faster [34]. This was however not observed in our case. The signal of M1 and M2 samples at $5 \mu \mathrm{M}$ concentration did not show the large drop found by Yu et al. 2004 (Figure 5, right panel) [36].
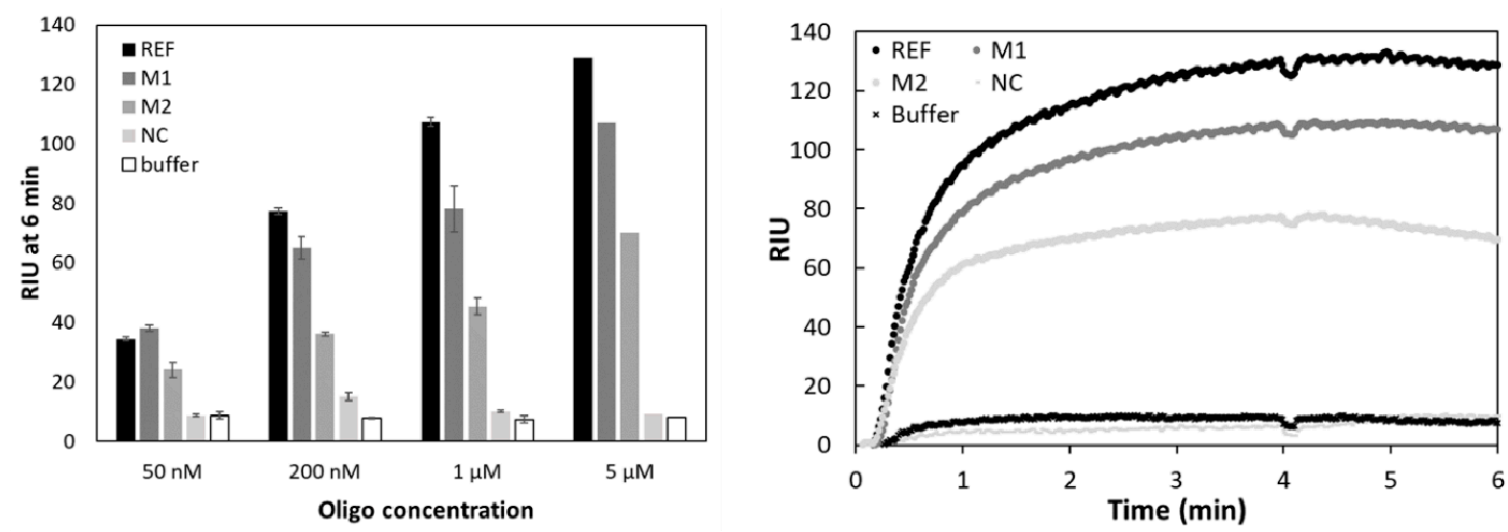

Figure 5. Refractive index units (RIU) measured after $6 \mathrm{~min}$ (Left panel) and binding curves at $5 \mu \mathrm{M}$ concentration (Right panel) for 100\% complementary (REF), one-mismatch (M1), two-mismatch (M2) and non-complementary (NC) sequences at four different concentrations. $n=3$ except for the $5 \mu \mathrm{M}$ case where only one set of measurements were carried out.

Usually, the observations regarding mismatched targets are interpreted as the ability of the sensor to distinguish one- or two-mismatch oligos from the target. Under circumstances, when the analyte is extremely pure, and its concentration is known, such ability can be indeed used to discriminate a 'mutant' nucleic acid sequence from the 'wild-type' [13,41]. However, when it comes to specifically detecting a target biomarker species from an entire community of bacteria, this 'ability' can prove to be less advantageous. Detection of $16 \mathrm{~S}$ rRNA genes from other non-oil degrading bacteria with one or two mismatches compared to the target species could lead to false-positive results, suggesting the presence of oil degrading bacteria when they are not present. Nevertheless, bacteria with only one or two mismatches in a given region of the $16 \mathrm{~S}$ rRNA are likely phylogenetically closely related and may even be functionally similar to each other. This appears to be the case for some of the Oleispira-related marine hydrocarbon degrading bacteria. Thalassolituus oleivorans strain MIL-1, contains only a single mismatch in the DP-targeted region of its $16 \mathrm{~S}$ rRNA in comparison to Oleispira antarctica RB-8, despite the overall sequence identity of $92 \%$ between the two strains. The 16S rRNA gene sequence of Spongiispira norvegica strain Gp_4_7.1, a closely related Oceanospirillacaea member had only two mismatches. Other closely related non-Oleispira strains reported to have similar physiology, Bermanella marisrubri strain RED65, and Oceaniserpentilla haliotis strain DSM 19503 had three and two mismatches, respectively. These observations illustrate that perhaps the approach reported here could be suitable to detect a suit of bacteria belonging to a functionally similar phylogenetic assemblage rather than a single species. Such a case was demonstrated by a chemiluminescence assay designed for marine Vibrio species, where the two selected Vibrio-specific probes (capture and signal) could differentiate 21 Vibrio vs. $10 \mathrm{non}-$ Vibrio species at $20 \mathrm{ng} / \mu \mathrm{L}(\sim 50 \mathrm{nM}, \mathrm{M} 16 \mathrm{Sr} \mathrm{RNA}=491.528 \mathrm{kDa})$ total RNA concentration [42]. Using a dual Oleispira-specific probe (both capture and detection probe to be designed specifically for Oleispira) may be an alternative to increase specificity. In any case, assessment of hybridization-based assays as performed by Da-Silva et al. [42] are necessary and should be carried out to validate results with our SPR system as well. 


\subsection{Testing Two Signal Amplification Strategies}

Magnetic beads (usually $1 \mu \mathrm{m}$ diameter) are routinely used for nucleic acid separation procedures. In SPR systems, usually smaller diameter gold-nanoparticles are used for signal amplification [31,37,38]. However, they are more expensive and due to small size are amenable to colloidal aggregation. We chose to work with larger beads coated with a streptavidin monolayer as a more cost-efficient and a more stable alternative. Streptavidin alone was shown to be a promising signal amplifier [14]. Larger beads will also result in greater signal amplification as long as they can be captured by the evanescent wave. The sensor chip in the SPR system used in this study uses an $830 \mathrm{~nm}$ light-emitting diode light source, providing a probing distance of approximately $400 \mathrm{~nm}$ into the medium. Thus the $500 \mathrm{~nm}$ beads, which are polydisperse, ranging in size from $50-450 \mathrm{~nm}$, with a mean of $200 \mathrm{~nm}$ are still within the range of detection of the SPREETA sensor. Another reason for focusing on using larger beads was that in the future, we plan to implement magnetic separation-based capture of bacterial rRNA prior to injection into the SPR system. This step can be carried out fastest by using larger diameter beads.

The two signal amplification strategies reported here were designed in accordance with the findings of Da-Silva et al. [39]. There the authors established that a prior hybridization of the biotin labeled capture probe with the target sequence followed by binding of this complex to the immobilized detection probe resulted in the highest response out of the three different strategies tested. Another possible approach would be to first conjugate the magnetic beads with the biotin labeled probes then perform the capture by hybridizing the target with the already conjugated probes (direct capture). However, indirect capture approach (hybridizing DNA-probe first then adding beads) seems better than direct capture (saturating beads with probes and then capturing by hybridization) according to [40]. Although the authors did not provide discussion regarding the possible reasons, this phenomenon may be explained in terms of relief of steric repulsion during binding of the oligonucleotides.

In this study, we first tested whether $500 \mathrm{~nm}$ diameter beads resulted in significant signal amplification in our SPR system, then a capture approach was also evaluated. An example binding curve for the two strategies is shown in Figure 6. The first 6 min of the capture approach (Figure 6B) were set at constant 0 as there was nothing being injected at this stage while the oligo-probe complex was being injected in the sequential approach. The first downward facing arrow in Figure $6 \mathrm{~A}$ points at the second injection step of the sequential approach, while in Figure $6 \mathrm{~B}$, it points at the first and only injection step of the capture approach. Both curves were recorded at $500 \mathrm{nM}$ PC oligo concentration and $50 \mu \mathrm{L} 1 \times$ bead amount.

The results showed that the magnetic beads indeed resulted in signal amplification (Figure 7) in comparison to injecting only the hybridized oligo-probe complex. Using $50 \mu \mathrm{L}$ of the $1 \times$ bead stock solution (100 $\mu \mathrm{g}$ beads) resulted in the highest amplification factor for both strategies (Table 3). 

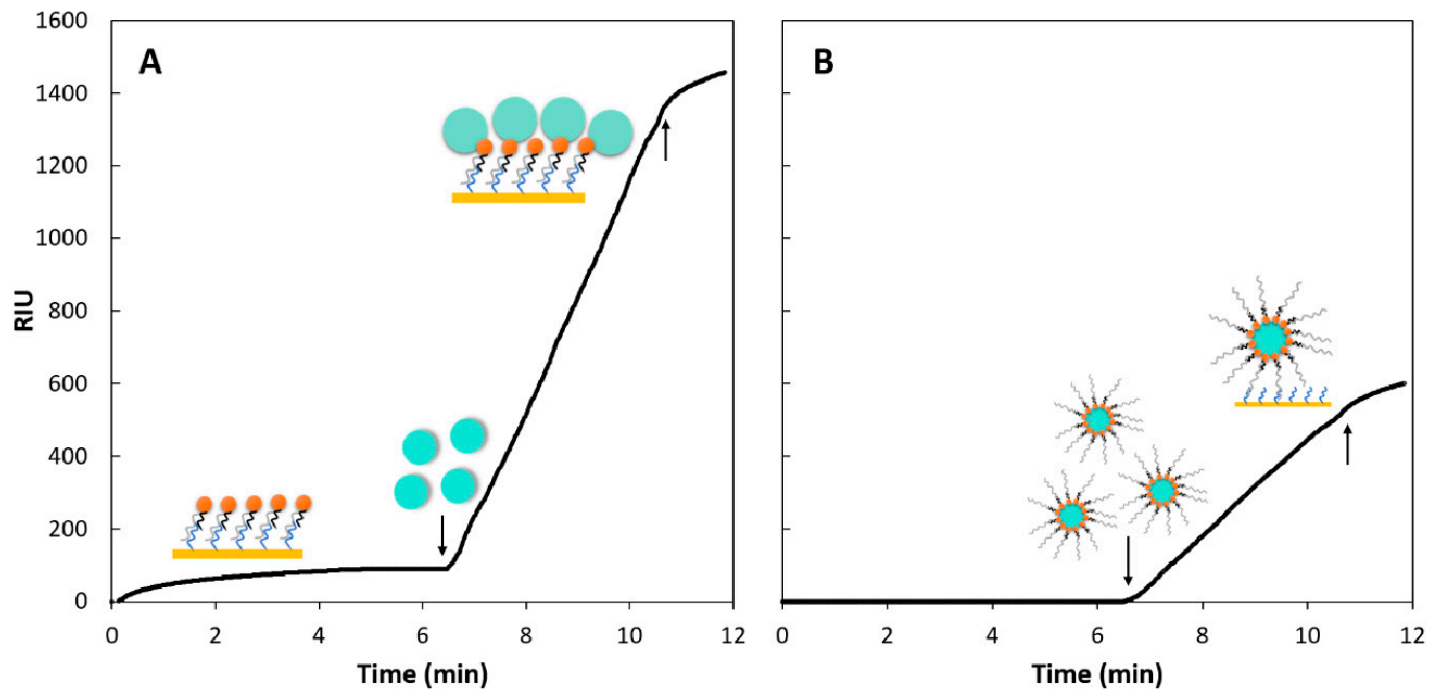

Figure 6. Refractive index units (RIU) recorded over time for the two amplification strategies, sequential (A) and capture (B) at identical target analyte (PC oligo) concentration (500 nM) and using the same amount of $1 \times$ beads $(50 \mu \mathrm{L}=100 \mu \mathrm{g}$ ). The illustrations correspond to the steps described in the Materials and Methods section and symbols are identical to those used in Figure 2. The $y$ axes were scaled to maximum 1600 RIU for both plots. The second, upward pointing arrow marks the 'flush' step, where the injection loop was flushed with buffer, hence no more analyte was being introduced from the injection loop to the sensor surface after this point.

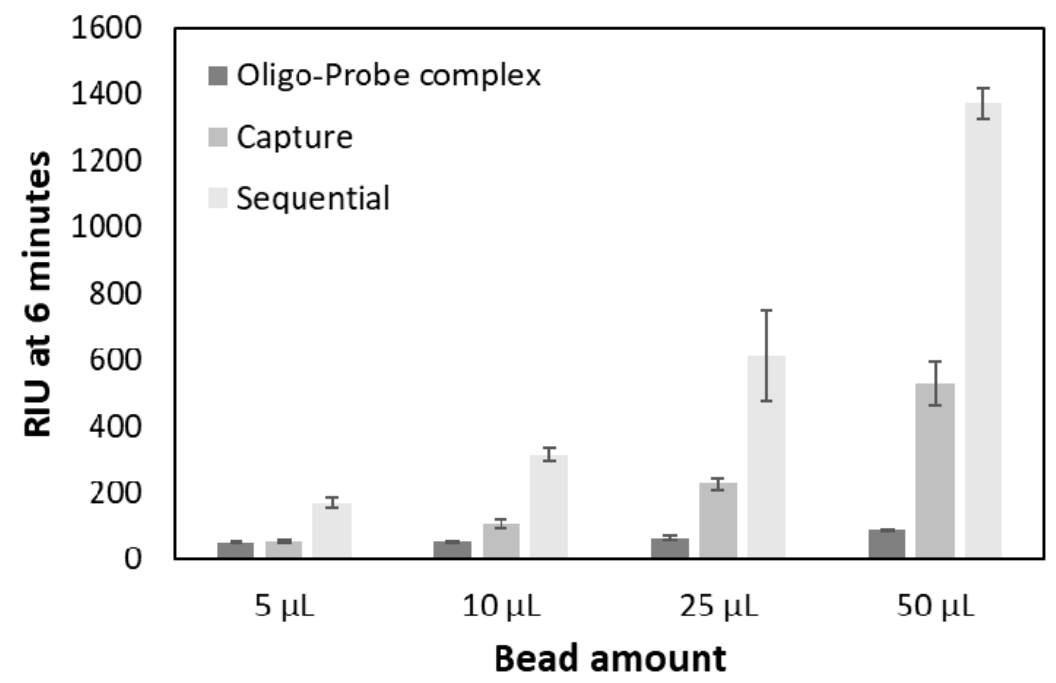

Figure 7. Comparison between the two signal amplification strategies at different bead amounts $(5,10$, 25 , and $50 \mu \mathrm{L})$ at constant oligo and probe concentration $(500 \mathrm{nM})$.

Table 3. The extent of signal amplification achieved using 4 different $1 \times$ bead amounts $(5,10$, 25 , or $50 \mu \mathrm{L}$ ) by either the capture or the sequential approach in comparison to no amplification. The amplification factors were calculated by dividing the signal of either sequential or capture enhanced refractive index units (RIU) by that of the RIU of oligo-probe complexes alone. The signal of bead solutions injected alone was subtracted prior to calculating the ratios $(n=3)$.

\begin{tabular}{ccccc}
\hline \multicolumn{4}{c}{ Amplification Factors $( \pm$ SD) } \\
\hline $\mathbf{5 \mu \mathrm { L }}$ & $\mathbf{1 0 \mu \mathrm { L }}$ & $\mathbf{2 5 \mu \mathrm { L }}$ & $\mathbf{5 0} \boldsymbol{\mu L}$ \\
\hline Capture & $1.1 \pm 0.03$ & $2.0 \pm 0.22$ & $3.5 \pm 0.31$ & $6.0 \pm 0.6$ \\
Sequential & $3.2 \pm 0.32$ & $5.8 \pm 0.38$ & $9.7 \pm 3.08$ & $15.5 \pm 0.70$ \\
\hline
\end{tabular}


However, the signal observed with the sequential approach was significantly higher than that of the capture approach. After the capture experiment, the supernatant was collected and injected separately to confirm the presence of 'leftover' oligo-probe complexes. Such experiments showed that most likely there is a low efficiency in capturing the hybridized oligo-probe complexes onto the beads as there was clear binding taking place when injecting the supernatant (data not shown). This indicated the need for further optimizing the protocol for oligo capture in our future experiments. There could have been reasons, other than the capture procedure not being optimized yet, for the observed differences between the two strategies. To illustrate in a realistic manner the difference between the capture and the sequential approach, particularly in the bead injection step, a size-proportional image was created (Figure 8). This representation clearly shows that unless the coverage of the magnetic bead with conjugated oligo-probe complexes is as high as that of the gold surface, the probability of the bead binding to the surface seems to be reduced in the capture scenario (Figure 8A). It is also worth noticing that while in the sequential scenario, a biotin-streptavidin binding takes place, which is a fast and extremely high-affinity process $\left(\mathrm{K}_{\mathrm{d}}\right.$ on the order of $\left.\approx 10^{-14} \mathrm{~mol} / \mathrm{L}\right)$, in the case of the capture approach, a morpholino-DNA hybridization must occur in order for the bead to become bound. While morpholino-DNA hybridization is still a high affinity binding process, the dissociation constants $\left(\mathrm{K}_{\mathrm{d}}\right)$ of this reaction were found to be over 3 orders of magnitude higher, on the order of $10^{-10} \mathrm{~mol} / \mathrm{L}(0.18 \pm 0.02 \mathrm{nM}$ for a 25 -nucleotide tetramethyl rhodamine labeled morpholino probe and $0.31 \pm 0.04 \mathrm{nM}$ for a 25 -nucleotide Alexa488 labeled morpholino probe) in a solution containing $10 \mathrm{mM}$ Tris (pH 7.5) and $1 \mathrm{mM}$ EDTA [41]. The same authors also determined hybridization rates of the morpholino probes to the target DNA in high salt $(150 \mathrm{mM} \mathrm{NaCl}$, similar to the DPBS-T buffer used in this study) and in low salt $(5 \mathrm{mM} \mathrm{NaCl})$ buffers and found that the rate was three times higher in the low salt $\left((15 \pm 2) \times 10^{5} \mathrm{M}^{-1} \cdot \mathrm{s}^{-1}\right)$ in comparison to the high salt $\left((4.8 \pm 0.5) \times 10^{5} \mathrm{M}^{-1} \cdot \mathrm{s}^{-1}\right)$. This suggests that lowering the salt concentration in our assay may improve the conditions for the binding of conjugated magnetic beads.

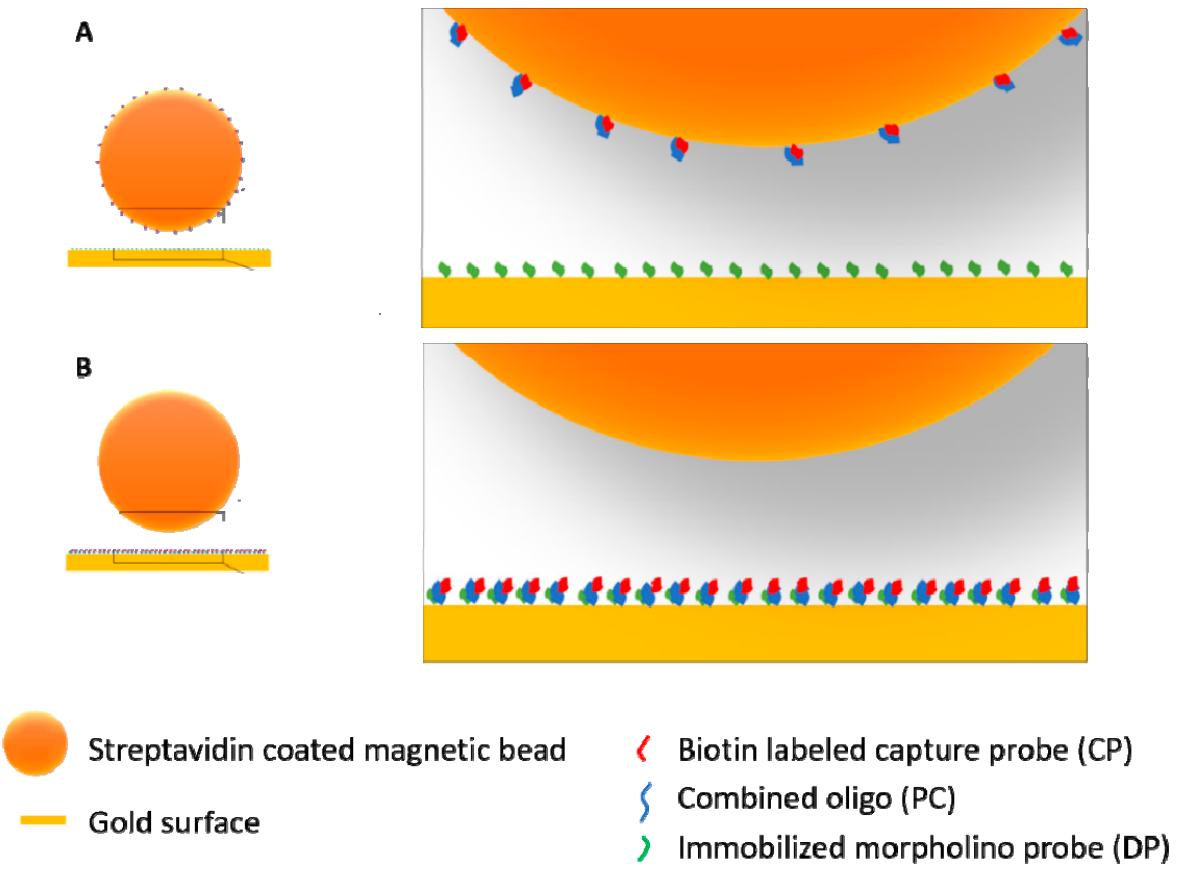

Figure 8. Illustration of the difference between the two signal amplification strategies, capture (A) and sequential (B) when it comes to the bead injection step. Oligo-probe conjugated beads are binding to the morpholino functionalized gold surface in the case of the capture approach (A) and bare-streptavidin coated beads are binding to the biotin labeled and immobilized oligo-probe complexes in the case of the sequential approach (B). The illustration is size-proportional, diameter of the magnetic particles is $500 \mathrm{~nm}$ while the length of DP and CP is $\sim 8 \mathrm{~nm}$ while PC is $\sim 17 \mathrm{~nm}$ long. 


\subsection{Testing the Detection Limits}

The average buffer signal over the 85 sample injections was $7.3 \pm 2.5$ RIU estimating an LOD at approximately $30 \mathrm{RIU}$ (considering the limit to be at three times the background signal). Taking this into account, the lowest detectable concentration of the Oleispira oligo (REF) without any amplification was $50 \mathrm{nM}(373 \mathrm{pg} / \mu \mathrm{L})$. Results from the serial dilution of the REF oligo are shown in Figure 9.

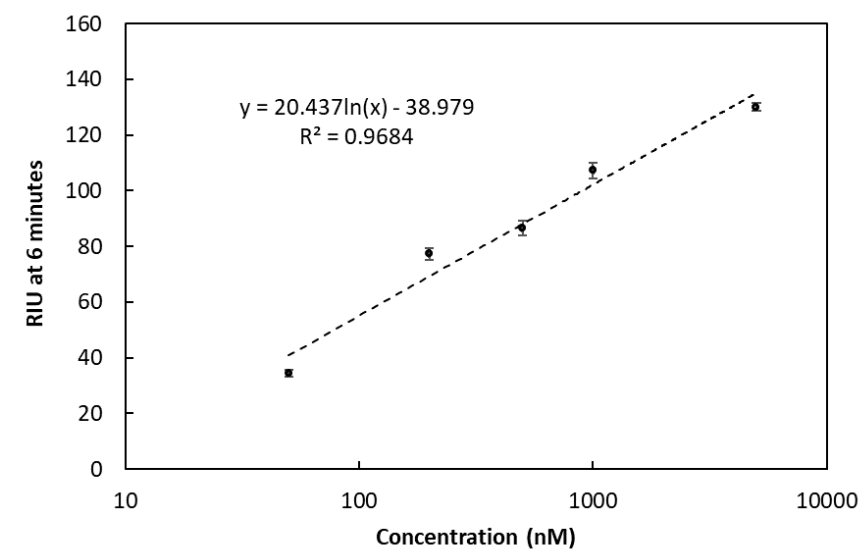

Figure 9. Refractive index units (RIU) at various concentrations (50, 200, 500, 1000, $5000 \mathrm{nM})$ of the Oleispira oligo (REF). For all measurement points $n=3$. Error bars represent SD.

Measured RIU values for the 10 -fold dilution series of the oligo-probe complex $(0.5,5,50,500 \mathrm{nM})$ using the sequential strategy at constant $50 \mu \mathrm{L} 1 \times$ bead stock solution are summarized in Figure 10 . A gradually decreasing signal was observed between $500-5 \mathrm{nM}$ analyte concentration with a larger drop from 5 to $0.5 \mathrm{nM}$. While the signal of the oligo-probe complex alone at $0.5 \mathrm{nM}$ concentration was below the 30 RIU established as the limit of detection, this level of the PC oligo was still detectable with magnetic bead-based signal amplification.

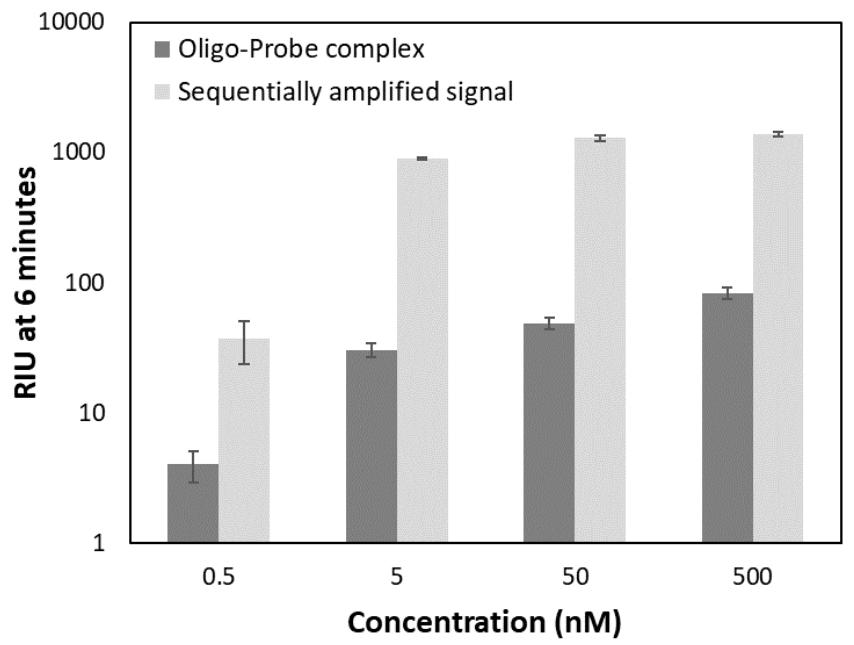

Figure 10. Concentration dependent response of the oligo-probe complex only and the signal of the same samples with sequential signal amplification approach using $50 \mu \mathrm{L} 1 \times$ bead stock. Amplified signal refers to the refractive index units (RIU values) recorded at $6 \mathrm{~min}$ of binding once the beads were injected.

The SPR instrument used in this study has been employed for antibody-based detection of smaller (domoic acid, $\mathrm{M}=311 \mathrm{~g} / \mathrm{mol}$ and cortisol, $\mathrm{M}=362 \mathrm{~g} / \mathrm{mol}$ ) and larger (staphylococcal enterotoxin $\mathrm{B}$, $\mathrm{SEB}, \mathrm{M}=28,366 \mathrm{Da})$ analytes with detection limits reaching $10 \mathrm{nM}(3.2 \mathrm{ng} / \mathrm{mL})$ for domoic acid, $1 \mathrm{nM}$ for cortisol $(0.36 \mathrm{ng} / \mathrm{mL})$, and $3.5 \mathrm{pM}(0.1 \mathrm{ng} / \mathrm{mL})$ for SEB, respectively [42-44]. Here we reported 
the first application of this portable SPR for oligonucleotide sensing, reaching detectable levels at $0.5 \mathrm{nM}$ for the PC oligo $(7.2 \mathrm{ng} / \mathrm{mL})$ with the sequential amplification strategy. The lowest measured concentration here $(0.5 \mathrm{nM})$ theoretically corresponds to $250 \mathrm{pg} / \mu \mathrm{L}$ of the $\sim 1500$ base long rRNA sequence of Oleispira (491.528 kDa), meaning that approximately $125 \mathrm{ng}$ rRNA would be necessary to be injected (given the $500 \mu \mathrm{L}$ injection volume) in an assay. This is approximately 10 times more than that can be expected to be obtained from marine microbial communities.

Several approaches can be considered to further improve the LOD of our method. One interesting possibility would be the application of external magnetic field, which resulted in a 10-fold improvement in LOD of an SPR-based immunoassay [45]. This is however not possible to implement on our current sensing system. Modifications that can be tested include exploring the effect of: (1) buffer composition used for hybridization and magnetic bead conjugation; (2) magnetic bead size; (3) adding a crowding agent PEG-20000; and (4) testing a competition assay. Eventually, a comparison between similar sized gold-nanoparticles and streptavidin coated magnetic beads may be worth exploring to investigate the potential role of plasmonic coupling in gold-nanoparticle based signal enhancement. Gold-nanoparticle based studies generally report lower LOD. For example, $1 \mathrm{pM}$ of fragmented $16 \mathrm{~S}$ rRNA was established as LOD with an SPRi system, where a similar sequential signal amplification strategy was used, however with streptavidin coated quantum dots ( 15-20 $\mathrm{nm}$ in diameter), instead of magnetic beads and an incubation time of $3 \mathrm{~h}$ [12]. Interestingly, streptavidin signal amplification alone was successful in reaching a similarly low detection limit ( $9 \mathrm{pM}$ of a 22-nucleotide long microRNA) in $30 \mathrm{~min}$ with the industry standard Biacore $\mathrm{X}^{\mathrm{TM}}$ instrument [14]. Another gold-nanoparticle $(20 \mathrm{~nm})$ based signal amplification SPR assay reached $0.01 \mathrm{ng} / \mathrm{mL}$ detection limit for $16 \mathrm{~S}$ rRNA of pathogenic bacteria [46]. A competition assay, where oligo-conjugated gold nanoparticles competed with the target analyte for the binding sites on the SPR surface reached a similar LOD $(0.5 \mathrm{nM})$ for a 22-nucleotide long target, miRNA-200b as our approach [31]. The reaction time in their study was $1 \mathrm{~h}$ in a stationary mode of a four-channel SPR instrument [47]. Lastly, an ultrasensitive surface plasmon resonance enhanced light scattering assay was reported to reach LOD of 2 attomoles ( $60 \mathrm{fM}, 50 \mu \mathrm{L}$ ) of miRNA-122 (22 nucleotide long) using a novel amplification scheme, taking advantage of specific RNA*DNA hybrid-binding antibodies [48].

\section{Conclusions}

The preliminary results reported here are promising for the use of morpholino probe based SPR detection of nucleic acids in monitoring bacterial species, hence oil pollution events based on the occurrence of bacterial indicators such as Oleispira antarctica RB-8. The applicability of a simple functionalization method using morpholino probes on sensor chip surfaces was confirmed showing excellent regeneration of the surface over 85 sample injections. Selectivity of the assay was comparable to that typically obtained with DNA oligos and other SPR-based morpholino functionalized sensors. Up to 16-fold signal amplification was achieved using streptavidin coated magnetic beads in a sequential injection manner. Detection limits were on the same order of magnitude ( $0.5 \mathrm{nM}$ for short oligonucleotides) as those reported for other portable SPR systems, with assay times half of previously reported.

Author Contributions: Conceptualization, A.B., S.D.S., C.E.F., and T.B.; Methodology, A.B. and S.D.S.; Investigation, A.B.; Writing-original draft preparation, A.B.; Writing-review and editing, T.B., S.D.S., and C.E.F.; Supervision, T.B., S.D.S., and C.E.F.; Project administration and funding acquisition, T.B.

Funding: This research was funded by the Research Council of Norway (RCN) through the Petromaks 2 Program, project no. 255494/E30.

Conflicts of Interest: The authors declare no conflict of interest. 


\section{References}

1. Medlin, L.K.; Orozco, J. Molecular techniques for the detection of organisms in aquatic environments, with emphasis on harmful algal bloom species. Sensors 2017, 17, 1184. [CrossRef] [PubMed]

2. McQuillan, J.S.; Robidart, J.C. Molecular-biological sensing in aquatic environments: Recent developments and emerging capabilities. Curr. Opin. Biotechnol. 2017, 45, 43-50. [CrossRef] [PubMed]

3. Ottesen, E.A. Probing the living ocean with ecogenomic sensors. Curr. Opin. Microbiol. 2016, 31, $132-139$. [CrossRef] [PubMed]

4. Yamahara, K.M.; Demir-Hilton, E.; Preston, C.M.; Marin, R., 3rd; Pargett, D.; Roman, B.; Jensen, S.; Birch, J.M.; Boehm, A.B.; Scholin, C.A. Simultaneous monitoring of faecal indicators and harmful algae using an in-situ autonomous sensor. Lett. Appl. Microbiol. 2015, 61, 130-138. [CrossRef] [PubMed]

5. Palchetti, I.; Mascini, M. Nucleic acid biosensors for environmental pollution monitoring. Analyst 2008, 133, 846-854. [CrossRef] [PubMed]

6. Justino, C.I.L.; Duarte, A.C.; Rocha-Santos, T.A.P. Recent progress in biosensors for environmental monitoring: A review. Sensors 2017, 17, 2918. [CrossRef] [PubMed]

7. Diercks-Horn, S.; Metfies, K.; Jäckel, S.; Medlin, L.K. The algadec device: A semi-automated rrna biosensor for the detection of toxic algae. Harmful Algae 2011, 10, 395-401. [CrossRef]

8. Soelberg, S.D.; Furlong, C.E. Biosensors and bioassays for ecological risk monitoring and assessment. In Environmental Toxicology; Laws, E., Ed.; Springer: New York, NY, USA, 2013; pp. 121-142.

9. Du, Y.; Dong, S. Nucleic acid biosensors: Recent advances and perspectives. Anal. Chem. 2017, 89, $189-215$. [CrossRef] [PubMed]

10. Nguyen, H.H.; Park, J.; Kang, S.; Kim, M. Surface plasmon resonance: A versatile technique for biosensor applications. Sensors 2015, 15, 10481-10510. [CrossRef] [PubMed]

11. Homola, J.; Yee, S.S.; Gauglitz, G. Surface plasmon resonance sensors: Review. Sens. Actuators B Chem. 1999, 54, 3-15. [CrossRef]

12. Foudeh, A.M.; Daoud, J.T.; Faucher, S.P.; Veres, T.; Tabrizian, M. Sub-femtomole detection of 16s rrna from legionella pneumophila using surface plasmon resonance imaging. Biosens. Bioelectron. 2014, 52, $129-135$. [CrossRef] [PubMed]

13. Li, Y.; Wark, A.W.; Lee, H.J.; Corn, R.M. Single-nucleotide polymorphism genotyping by nanoparticle-enhanced surface plasmon resonance imaging measurements of surface ligation reactions. Anal. Chem. 2006, 78, 3158-3164. [CrossRef] [PubMed]

14. Ding, X.; Yan, Y.; Li, S.; Zhang, Y.; Cheng, W.; Cheng, Q.; Ding, S. Surface plasmon resonance biosensor for highly sensitive detection of microrna based on DNA super-sandwich assemblies and streptavidin signal amplification. Anal. Chim. Acta 2015, 874, 59-65. [CrossRef] [PubMed]

15. Scholin, C.; Doucette, G.; Jensen, S.; Roman, B.; Pargett, D.; Marin, R.; Preston, C.; Jones, W.; Feldman, J.; Everlove, C.; et al. Remote detection of marine microbes, small invertebrates, harmful algae, and biotoxins using the environmental sample processor (esp). Oceanography 2009, 22, 158-167. [CrossRef]

16. Chinowsky, T.M.; Soelberg, S.D.; Baker, P.; Swanson, N.R.; Kauffman, P.; Mactutis, A.; Grow, M.S.; Atmar, R.; Yee, S.S.; Furlong, C.E. Portable 24-analyte surface plasmon resonance instruments for rapid, versatile biodetection. Biosens. Bioelectron. 2007, 22, 2268-2275. [CrossRef] [PubMed]

17. Kroger, S.; Law, R.J. Biosensors for marine applications. We all need the sea, but does the sea need biosensors? Biosens. Bioelectron. 2005, 20, 1903-1913. [PubMed]

18. Kröger, S.; Parker, E.R.; Metcalfe, J.D.; Greenwood, N.; Forster, R.M.; Sivyer, D.B.; Pearce, D.J. Sensors for observing ecosystem status. Ocean Sci. 2009, 5, 523-535. [CrossRef]

19. Bagi, A.; Knapik, K.; Nilsen, M.M.; Krolicka, A.; Boccadoro, C.; Baussant, T. Environmental surveillance of marine systems using genosensors: Application to offshore activities. In Oilfield Microbiology; Whitby, C., Skovhus, T.L., Eds.; CRC Press: Boca Raton, FL, USA, In Prep.

20. Kube, M.; Chernikova, T.N.; Al-Ramahi, Y.; Beloqui, A.; Lopez-Cortez, N.; Guazzaroni, M.E.; Heipieper, H.J.; Klages, S.; Kotsyurbenko, O.R.; Langer, I.; et al. Genome sequence and functional genomic analysis of the oil-degrading bacterium Oleispira antarctica. Nat. Commun. 2013, 4, 2156. [CrossRef] [PubMed]

21. Gentile, G.; Bonsignore, M.; Santisi, S.; Catalfamo, M.; Giuliano, L.; Genovese, L.; Yakimov, M.M.; Denaro, R.; Genovese, M.; Cappello, S. Biodegradation potentiality of psychrophilic bacterial strain Oleispira antarctica rb-8(t). Mar. Pollut. Bull. 2016, 105, 125-130. [CrossRef] [PubMed] 
22. Królicka, A.; Boccadoro, C.; Mæland, M.; Preston, C.; Birch, J.; Scholin, C.; Baussant, T. Detection of oil leaks by quantifying hydrocarbonoclastic bacteria in cold marine environments using the environmental sample processor. In Proceedings of the 37th AMOP Technical Seminar on Environmental Contamination and Response, Canmore, AB, Canada, 3-5 June 2014.

23. Sipova, H.; Homola, J. Surface plasmon resonance sensing of nucleic acids: A review. Anal. Chim. Acta 2013, 773, 9-23. [CrossRef] [PubMed]

24. Hu, W.; Fu, G.; Kong, J.; Zhou, S.; Scafa, N.; Zhang, X. Advancement of nucleic acid biosensors based on morpholino. Am. J. Biomed. Sci. 2015, 7, 40-51. [CrossRef]

25. Moulton, H.M.; Moulton, J.D. Morpholino Oligomers: Methods and Protocols, 1st ed.; Humana Press: New York, NY, USA, 2017; p. 284.

26. Levicky, R.; Koniges, U.; Tercero, N. Diagnostic applications of morpholinos and label-free electrochemical detection of nucleic acids. Methods Mol. Biol. 2017, 1565, 181-190. [PubMed]

27. Soelberg, S.D.; Chinowsky, T.; Geiss, G.; Spinelli, C.B.; Stevens, R.; Near, S.; Kauffman, P.; Yee, S.; Furlong, C.E. A portable surface plasmon resonance sensor system for real-time monitoring of small to large analytes. J. Ind. Microbiol. Biotechnol. 2005, 32, 669-674. [CrossRef] [PubMed]

28. Quast, C.; Pruesse, E.; Yilmaz, P.; Gerken, J.; Schweer, T.; Yarza, P.; Peplies, J.; Glöckner, F.O. The silva ribosomal rna gene database project: Improved data processing and web-based tools. Nucleic Acids Res. 2013, 41, D590-D596. [CrossRef] [PubMed]

29. Sun, C.P.; Liao, J.C.; Zhang, Y.H.; Gau, V.; Mastali, M.; Babbitt, J.T.; Grundfest, W.S.; Churchill, B.M.; McCabe, E.R.; Haake, D.A. Rapid, species-specific detection of uropathogen 16s rdna and rrna at ambient temperature by dot-blot hybridization and an electrochemical sensor array. Mol. Genet. Metab. 2005, 84, 90-99. [CrossRef] [PubMed]

30. Liao, T.; Li, X.; Tong, Q.; Zou, K.; Zhang, H.; Tang, L.; Sun, Z.; Zhang, G.J. Ultrasensitive detection of micrornas with morpholino-functionalized nanochannel biosensor. Anal. Chem. 2017, 89, 5511-5518. [CrossRef] [PubMed]

31. Hong, L.; Lu, M.; Dinel, M.P.; Blain, P.; Peng, W.; Gu, H.; Masson, J.F. Hybridization conditions of oligonucleotide-capped gold nanoparticles for spr sensing of microrna. Biosens. Bioelectron. 2018, 109, 230-236. [CrossRef] [PubMed]

32. Tercero, N.; Wang, K.; Gong, P.; Levicky, R. Morpholino monolayers: Preparation and label-free DNA analysis by surface hybridization. J. Am. Chem. Soc. 2009, 131, 4953-4961. [CrossRef] [PubMed]

33. Liu, C.; Zeng, G.M.; Tang, L.; Zhang, Y.; Li, Y.P.; Liu, Y.Y.; Li, Z.; Wu, M.S.; Luo, J. Electrochemical detection of pseudomonas aeruginosa $16 \mathrm{~s}$ rrna using a biosensor based on immobilized stem-loop structured probe. Enzym. Microb. Technol. 2011, 49, 266-271. [CrossRef] [PubMed]

34. Heng, J.B.; Ho, C.; Kim, T.; Timp, R.; Aksimentiev, A.; Grinkova, Y.V.; Sligar, S.; Schulten, K.; Timp, G. Sizing DNA using a nanometer-diameter pore. Biophys. J. 2004, 87, 2905-2911. [CrossRef] [PubMed]

35. Tercero, N.; Wang, K.; Levicky, R. Capacitive monitoring of morpholino-DNA surface hybridization: Experimental and theoretical analysis. Langmuir 2010, 26, 14351-14358. [CrossRef] [PubMed]

36. Yu, F.; Yao, D.; Knoll, W. Oligonucleotide hybridization studied by a surface plasmon diffraction sensor (spds). Nucleic Acids Res. 2004, 32, e75. [CrossRef] [PubMed]

37. Parab, H.J.; Jung, C.; Lee, J.H.; Park, H.G. A gold nanorod-based optical DNA biosensor for the diagnosis of pathogens. Biosens. Bioelectron. 2010, 26, 667-673. [CrossRef] [PubMed]

38. Hao, K.; He, Y.; Lu, H.; Pu, S.; Zhang, Y.; Dong, H.; Zhang, X. High-sensitive surface plasmon resonance microrna biosensor based on streptavidin functionalized gold nanorods-assisted signal amplification. Anal. Chim. Acta 2017, 954, 114-120. [CrossRef] [PubMed]

39. Da-Silva, E.; Barthelmebs, L.; Baudart, J. Development of a pcr-free DNA-based assay for the specific detection of vibrio species in environmental samples by targeting the $16 \mathrm{~s}$ rrna. Environ. Sci. Pollut. Res. Int. 2017, 24, 5690-5700. [CrossRef] [PubMed]

40. Wages, J.M., Jr.; Wages, G.M.; Matthews, P.; Weller, D.; Summerton, J. Affinity purification of rna: Sequence-specific capture by nonionic morpholino probes. Biotechniques 1997, 23, 1116-1121. [CrossRef] [PubMed]

41. Xiong, Y.; McQuistan, T.J.; Stanek, J.W.; Summerton, J.E.; Mata, J.E.; Squier, T.C. Detection of unique ebola virus oligonucleotides using fluorescently-labeled phosphorodiamidate morpholino oligonucleotide probe pairs. Anal. Biochem. 2018, 557, 84-90. [CrossRef] [PubMed] 
42. Stevens, R.C.; Soelberg, S.D.; Near, S.; Furlong, C.E. Detection of cortisol in saliva with a flow-filtered, portable surface plasmon resonance biosensor system. Anal. Chem. 2008, 80, 6747-6751. [CrossRef] [PubMed]

43. Soelberg, S.D.; Stevens, R.C.; Limaye, A.P.; Furlong, C.E. Surface plasmon resonance detection using antibody-linked magnetic nanoparticles for analyte capture, purification, concentration, and signal amplification. Anal. Chem. 2009, 81, 2357-2363. [CrossRef] [PubMed]

44. Stevens, R.C.; Soelberg, S.D.; Eberhart, B.-T.L.; Spencer, S.; Wekell, J.C.; Chinowsky, T.M.; Trainer, V.L.; Furlong, C.E. Detection of the toxin domoic acid from clam extracts using a portable surface plasmon resonance biosensor. Harmful Algae 2007, 6, 166-174. [CrossRef]

45. Wang, Y.; Dostalek, J.; Knoll, W. Magnetic nanoparticle-enhanced biosensor based on grating-coupled surface plasmon resonance. Anal. Chem. 2011, 83, 6202-6207. [CrossRef] [PubMed]

46. Melaine, F.; Saad, M.; Faucher, S.; Tabrizian, M. Selective and high dynamic range assay format for multiplex detection of pathogenic pseudomonas aeruginosa, salmonella typhimurium, and legionella pneumophila rnas using surface plasmon resonance imaging. Anal. Chem. 2017, 89, 7802-7807. [CrossRef] [PubMed]

47. Zhao, S.S.; Bukar, N.; Toulouse, J.L.; Pelechacz, D.; Robitaille, R.; Pelletier, J.N.; Masson, J.F. Miniature multi-channel spr instrument for methotrexate monitoring in clinical samples. Biosens. Bioelectron. 2015, 64, 664-670. [CrossRef] [PubMed]

48. Yang, C.T.; Pourhassan-Moghaddam, M.; Wu, L.; Bai, P.; Thierry, B. Ultrasensitive detection of cancer prognostic mirna biomarkers based on surface plasmon enhanced light scattering. ACS Sens. 2017, 2, 635-640. [CrossRef] [PubMed]

(C) 2018 by the authors. Licensee MDPI, Basel, Switzerland. This article is an open access article distributed under the terms and conditions of the Creative Commons Attribution (CC BY) license (http:/ / creativecommons.org/licenses/by/4.0/). 